\section{1st Annual Meeting Call for Abstracts}

The WTSA's 41st Annual Meeting will be held at the Fairmont Chateau Whistler in Whistler, British Columbia, from June 24 to 27, 2015. Abstract submissions are now being

\section{The American Board of Thoracic Surgery}

\section{Notices}

The part I (written) examination will be held on Monday, November 14, 2014, at multiple sites throughout the United States using an electronic format. The closing date for registration is August 15, 2014. Those wishing to be considered for examination must apply online at www.abts.org.

To be admissible for the Part II (oral) examination, a candidate must have successfully completed the Part I (written) examination.

A candidate applying for admission to the certifying examination must fulfill all the requirements of the Board in force at the time the application is received. Please address all communications to the American Board of Thoracic Surgery, 633 North St Clair Street, Suite 2320, Chicago, IL 60611 (telephone: 312-202-5900).

\section{Requirements for Maintenance of Certification}

Diplomates of the American Board of Thoracic Surgery (ABTS) who plan to participate in the Maintenance of Certification (MOC) process as Certified-Active must hold an unrestricted medical license in the locale of their practice and privileges in a hospital accredited by the JCAHO (or other organization recognized by the ABTS). In addition, a valid ABTS certificate is an absolute requirement for entrance into the Maintenance of Certification process. If your certificate has expired, the only pathway for renewal of a certificate is to take and pass the Part I (written) and the Part II (oral) certifying examinations. The names of individuals who have not maintained their certificate will no longer be published in the American Board of Medical Specialties Directories. Diplomates' names will be published upon successful completion of the Maintenance of Certification process. accepted for presentation consideration at the 2015 WTSA Annual Meeting through Monday, January 5, 2015, at 11:59 PM Pacific Standard Time. Visit the WTSA Web site at www.westernthoracic.org to view author instructions and to submit abstracts.

The CME requirements are 150 Category I credits earned over a 5-year period. At least half of these CME hours need to be in the broad area of thoracic surgery. Category II credits are not accepted. Interested individuals should refer to the Board's Web site (www.abts.org) for a complete description of acceptable CME credits. Diplomates will be expected to submit verification of CME earned.

Diplomates in the Maintenance of Certification process will need to provide a summary of their major cases performed during the year prior to application. The practice review should not exceed 100 cases.

Diplomates in the Maintenance of Certification process will be required to complete all sections of the SESATS selfassessment examination. It is not necessary for Diplomates to purchase SESATS individually, because it will be sent to them after their application has been approved.

Diplomates may apply for Maintenance of Certification in the year their certificate expires, or if they wish to do so, they may apply up to two years before it expires. However, the new certificate will be dated 10 years from the date of expiration of their original certificate or most recent recertification certificate. In other words, going through the Maintenance of Certification process early does not alter the 10-year validation. Diplomates certified prior to 1976 (the year that time-limited certificates were initiated) are also required to participate in MOC if they wish to maintain valid certificates.

The deadline for submission of application for the Maintenance of Certification is May 10 of each year. All ABTS diplomates will receive a letter from the Board outlining their individual timeline and MOC requirements. A brochure outlining the rules and requirements for Maintenance of Certification in thoracic surgery is available upon request from the American Board of Thoracic Surgery, 633 North St. Clair Street, Suite 2320, Chicago, IL 60611; telephone (312) 202-5900; fax (312) 202-5960; E-mail info@abts.org. This booklet is also published on the Web site: www.abts.org.

applicants. Please visit the TSFRE Awards Page or www.tsfre.org for detailed information and applicant guidelines.

\section{- TSFRE Alley-Sheridan Scholarships}

A. Leadership Program in Health Policy and Management: TSFRE offers up to ten partial scholarships of $\$ 2,500$ toward the $\$ 5,200$ cost to attend the Leadership
Thoracic Surgery Foundation for Research and Education (TSFRE) is offering several 2015 awards to qualified

\section{Thoracic Surgery Foundation for Research and Education Awards}


Program in Health Policy and Management at the Heller School of Public Policy and Management at Brandeis University. Deadline: March 15, 2015

B. Surgeons as Educators: TSFRE will support up to two scholarships of $\$ 2,500$ toward the cost of tuition to attend the
Surgeons as Educators course hosted by the American College of Surgeons. Deadline: TBD

We look forward to receiving your applications. If you have any additional questions, please contact Priscilla Kennedy, TSFRE Executive Director, at 312-202-5868 or by E-mail at pkennedy@tsfre.org. 